\title{
Morbimortality in adult patients with septic arthritis: a three-year hospital-based study
}

\author{
Julien Ferrand', Youssef El Samad², Benoit Brunschweiler', Franck Grados', Nassima Dehamchia-Rehailia', \\ Alice Séjourne ${ }^{1}$, Jean-Luc Schmit ${ }^{2}$, Antoine Gabrion ${ }^{3}$, Patrice Fardellone ${ }^{1}$ and Julien Paccou ${ }^{1 *}$
}

\begin{abstract}
Background: The objective of this ambispective study was to determine outcomes and associated factors for adult patients with confirmed septic arthritis (SA).

Methods: All adult patients admitted to Amiens University Hospital between November 2010 and December 2013 with confirmed SA were included in the study. Patients with prosthetic joint infections were excluded. A statistical analysis was performed in order to identify risk factors associated with a poor outcome (including mortality directly attributable to $S A$ ).

Results: A total of 109 patients (mean \pm SD age: $60.1 \pm 20.1 ; 74$ male/35 females) were diagnosed with SA during the study period. The most commonly involved sites were the small joints $(n=34,31.2 \%)$ and the knee $(n=25,22$. $9 \%)$. The most frequent concomitant conditions were cardiovascular disease $(n=45,41.3 \%)$ and rheumatic disease ( $n=39,35.8 \%$ ). One hundred patients (91.7\%) had a positive microbiological culture test, with Staphylococcus aureus as the most commonly detected pathogen $(n=59,54.1 \%)$. Mortality directly attributable to SA was relatively infrequent $(n=6,5.6 \%)$ and occurred soon after the onset of SA (median [range]: 24 days [1-42]). Major risk factors associated with death directly attributable to SA were older age $(p=0.023)$, high C-reactive protein levels $(p=0.002)$ , diabetes mellitus $(p=0.028)$, rheumatoid arthritis and other inflammatory rheumatic diseases $(p=0.021)$, confusion on admission ( $p=0.012)$, bacteraemia $(p=0.015)$, a low creatinine clearance rate $(p=0.009)$ and the presence of leg ulcers/eschars ( $p=0.003$ ). The median duration of follow-up (in patients who survived for more than 6 months) was 17 months [6-43]. The proportion of poor functional outcomes was high (31.8\%). Major risk factors associated with a poor functional outcome were older age (0.049), hip joint involvement $(p=0.003)$, the presence of leg ulcers/eschars ( $p=0.012)$, longer time to presentation (0.034) and a low creatinine clearance rate $(p=0.013)$.
\end{abstract}

Conclusions: In a university hospital setting, SA is still associated with high morbidity and mortality rates.

Keywords: Septic arthritis, Clinical characteristics, Mortality, Poor functional outcome, Risk factors, C-reactive protein

\section{Background}

Septic arthritis (SA) is the most serious condition in the differential diagnosis of an inflamed, swollen joint [1-3]. The diagnosis of SA can be challenging even for doctors skilled in the management of musculoskeletal disease [1-3]. The incidence of SA in the USA and Western Europe has variously been reported as between 2 and 10 per 100,000 patient-years [4-7]. The incidence rises in specific patient populations; in patients with rheumatoid

\footnotetext{
* Correspondence: julienpaccou@yahoo.fr

'Department of Rheumatology, Amiens University Hospital, F-80054 Amiens, France

Full list of author information is available at the end of the article
}

arthritis (RA), the annual incidence has been estimated at 70 cases per 100,000 patient-years [8,9]. Additional risk factors for SA include low socioeconomic status, previous rheumatic disease (e.g. RA, osteoarthritis, crystal arthropathy, and other forms of inflammatory arthritis), previous surgery, diabetes mellitus, leg ulcers, intravenous drug abuse, alcohol abuse, intra-articular corticosteroid injection, and (possibly) human immunodeficiency virus infection [10-12]. Although all age groups can be affected, SA mainly usually arises in elderly people and very young children [1-3]. In all age and risk groups, the most frequent causative organism is 
Staphylococcus aureus, followed by other Gram-positive bacteria (including streptococci) [1-3].

Septic arthritis is a medical emergency, and so delayed or inadequate treatment can lead to irreversible joint destruction and thus substantial morbidity and mortality [1-3]. In the literature, the reported mortality rate for SA ranges from 4 to $42 \%$ [13-15], with values as high as $50 \%$ in polyarticular disease [12]. Morbidity is also substantial, with persistent joint dysfunction occurring in up to $30 \%$ of cases $[16,17]$. However, very few detailed studies of morbidity, mortality and outcomes in adult patients with SA have been published in the last 20 years. The primary objective of the present study was therefore to identify (i) characteristics and outcomes in adult patients with SA admitted to a university hospital, and (ii) the risk factors associated with poor outcomes (including mortality).

\section{Methods}

\section{Design and setting}

This hospital-based, ambispective study was conducted at Amiens University Hospital (Amiens, France). Episodes of SA in adult patients (aged $\geq 16$ years) attending this tertiary hospital over a three-year period (November 2010 to December 2013) were identified. Patients with prosthetic joint SA or patients with SA following surgical procedures were excluded from the study, as were patients with diabetes-related foot infections. The study was designed in accordance with the ethical standards of our hospital Ethics Committee (Amiens University Hospital). In view of the study's design, no written informed consent to participation was necessary in accordance with our ethical committee. Indeed, this is an observational study with usual care.

\section{Case definition}

All included patients met one of Newman's diagnostic criteria for SA [18]: (A) isolation of an organism from an affected joint, (B) isolation of an organism from another site in a patient with a concomitant swollen, inflamed joint, (C) no organism isolated but clinical features and turbid joint fluid in patients having undergone prior antibiotic therapy, and (D) no organism isolated but histological or radiologic evidence consistent with SA.

Moreover, organisms were isolated and identified with conventional biochemical assays and tests in Amiens University Hospital's microbiology laboratory.

\section{Case identification and data collection}

The following methods were applied to identify cases: (i) consecutive patients with SA diagnosed between November 2010 and December 2013 were prospectively recorded in the diagnosis registry by the attending clinicians (in the rheumatology, orthopaedics and infectious disease departments); (ii) patients were identified retrospectively (in January 2014) by checking the hospital activity index (HAI) over a three-year period (November 2010-December 2013).

The patients' case notes were reviewed from January 2014 onwards by using a structured pro forma report form. The following items of information were extracted: age, gender, concomitant conditions, presentation, assessments, investigations, pathogen(s) responsible, treatments and outcomes. If several joints were involved, the patient was classified as a function of the predominantly affected joint.

\section{Data on disease outcomes}

Data on disease outcomes (collected between January 2014 and July 2014) were obtained from medical records and, if necessary, from the patients in a phone interview. When patients could not be contacted or were unable to answer questions, a family member or general practitioner was interviewed instead. The disease outcomes questionnaire included a number of closed questions: "Is the patient still alive?"; "When did death occur?"; "What was the cause of death?"; "Has your joint function worsened or have you developed any new limitations in joint function that can be ascribed to SA".

After a review of the medical records (and a phone interview, if necessary), the patient outcome was classified as "poor" in the event of death. We sought to distinguish between deaths directly attributable to septic arthritis and those due to other causes. We considered that the death was related to SA when this was indicated in the patient's case notes. The joint outcome was classified as "poor" in cases of amputation, arthrodesis, prosthetic surgery or severe functional deterioration reported by the patient. If several joints were involved, the patient was analyzed as a function of the predominantly affected joint.

\section{Statistical analysis}

Statistical analysis was performed using SAS software (version 9.3, SAS Institute Inc., Cary NC, USA). Continuous variables are reported as the median, minimum, maximum, and missing values; categorical variables are reported as the frequency and percentage. All tests were two-sided, with a significance threshold set to $p<0.05$. The various groups were compared using a chi-square test or Fisher's exact test for categorical variables, and either an analysis of variance (or Student's $t$ test, for two groups) or a Kruskal-Wallis test (or a Mann-Whitney test, for two groups) for continuous variables.

A univariate logistic regression model was used to screen for risk factors that were predictive of mortality attributable directly to SA. Likewise, a univariate logistic 
regression model was used to screen for risk factors that were predictive of a poor functional outcome.

The following potential risk factors were tested: age, confusion on admission, time to presentation (days), open and arthroscopic surgery, diabetes mellitus, cardiovascular disease, cancer (pre-existing or concomitant), concomitant or pre-existing skin involvement (eschars and/or leg ulcers), previous RA and other forms of inflammatory arthritis, joint involvement (hip, knee, multiple or small joints), organism (Staphylococcus aureus), bacteraemia, C-reactive protein (CRP) and the measured creatinine clearance rate (evaluated according to the Modification of Diet in Renal Disease equation).

\section{Results}

Identification and selection of cases

A total of 410 adult patients were identified for the study period (Fig. 1). Twenty-two of the 410 patients were identified in the prospective diagnosis registry but not in the retrospective review. Two hundred and ninety-six patients were excluded following review of their case notes: 143 had prosthetic joint SA, 27 were aged under 16, 15 had diabetes-related foot infections, 7 had developed SA following surgery, 7 had osteomyelitis, 7 had infectious spondylodiscitis, 45 were duplicate cases (prospective records) and 45 had been misdiagnosed with SA (cases of RA, reactive arthritis, gout, etc.). Hence,

\section{Excluded: $\mathrm{n}=296$}

- Prosthetic joint SA $(n=143)$

- Diabetes-related foot infections $(\mathrm{n}=15)$

- Misdiagnosed with SA $(n=45)$

- Osteomyelitis $(\mathrm{n}=7)$

- Infectious spondylodiscitis $(\mathrm{n}=7)$

- SA following surgery $(n=7)$

- Age < 16 years $(\mathrm{n}=27)$

- Duplicate (prospective record) $(n=45)$

- Others $(n=7)$
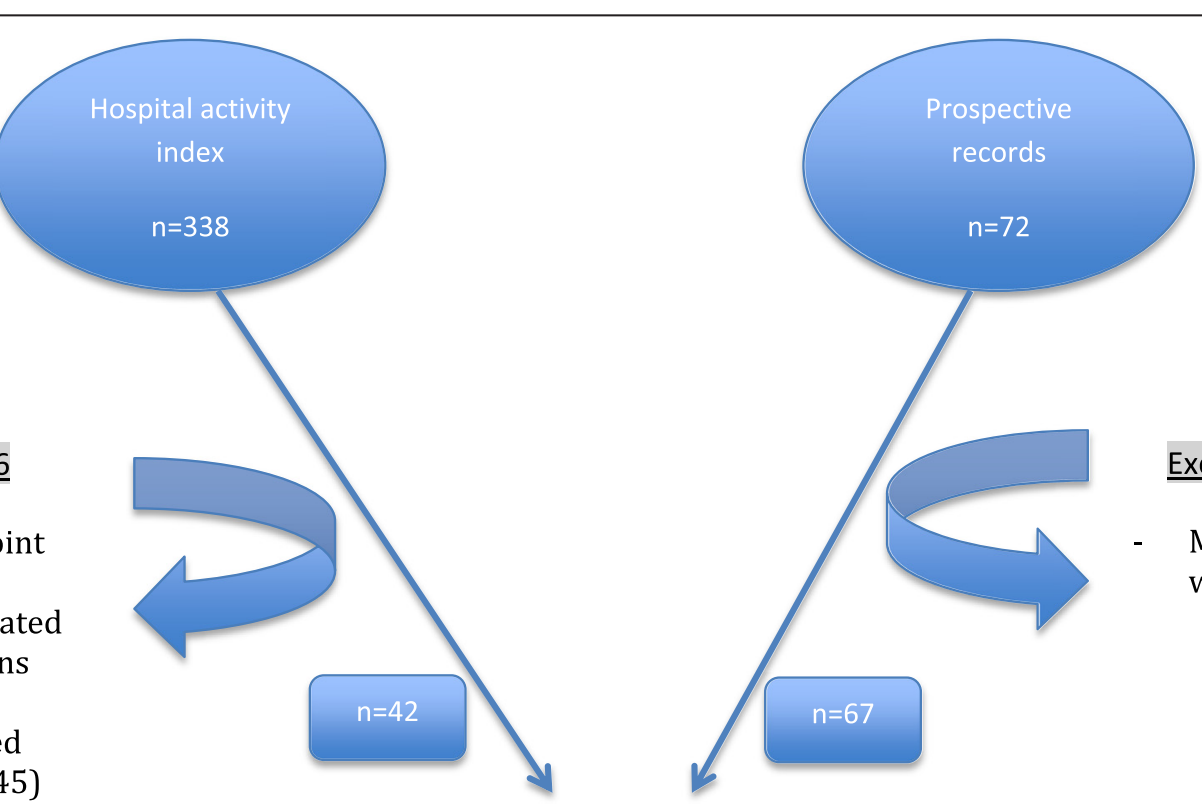

Excluded: $n=5$

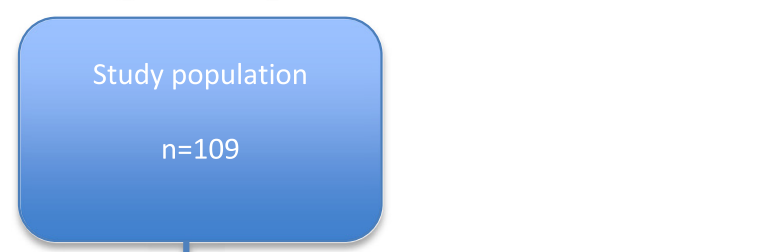

Misdiagnosed with $S A(n=5)$

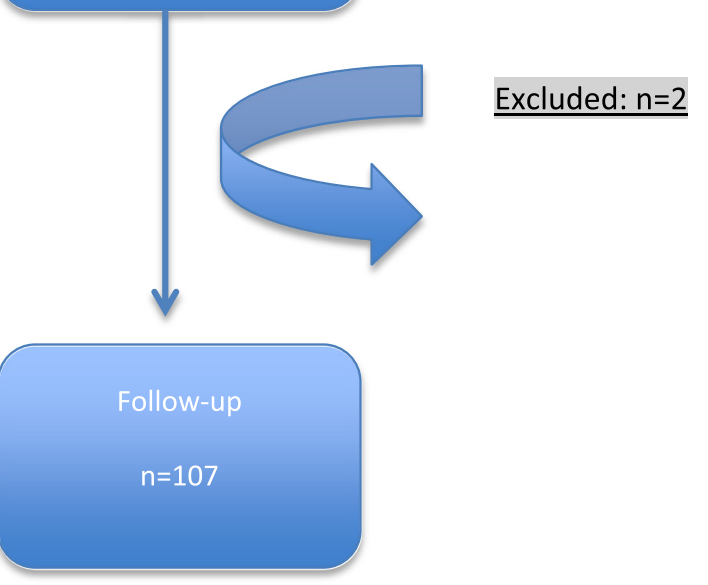

Fig. 1 Study flow chart 
data on the remaining 109 adult patients with confirmed SA (including 11 with multiple joint involvements) were analyzed. Most of the patients had been referred to our rheumatology $(n=51,47.8 \%)$ and orthopaedics departments $(n=37,33.9 \%)$, with fewer referrals to our infectious disease $(n=20,18.3 \%)$ and geriatric medicine departments $(n=1,<1 \%)$ (Table 1$)$.

\section{Demographics, affected joints and pathogens}

As mentioned above, 109 patients (with a total of 130 infected joints) were included (median [range] age: 62 [16-96]; $n=74$ males, $67.9 \%$; median [range] BMI: 25 $[14.5-48] \mathrm{kg} / \mathrm{m}^{2}$ ) (Table 1). In terms of the Newman criteria, 91 of the 109 patients $(83.5 \%)$ were in group A, with 9 in group B, 5 in group $C$ and 4 in group D. Joint involvement is summarized in Table 2. The most frequently involved sited were the small joints (fingers and toes) $(n=34,31.2 \%)$, followed by the knee $(n=25$, $22.9 \%)$, the shoulder ( $n=16,14.7 \%)$ and the hip ( $n=$ 12, $11.0 \%)$. Patients with small joint involvement differed significantly in terms of age $(52.0 \pm 22.6$ vs. $63.3 \pm$ 18.4, $p<0.01)$ and most of them were referred to the orthopaedic department $(n=28,82.3 \%)$ (Table 1$)$.

The data on bacterial isolates are summarized in Table 3. Staphylococcus aureus was the most commonly isolated bacteria $(n=54)$. Nine of the latter cases were due to methicillin-resistant strains. Streptococci and Pasteurella were involved in 11 and 7 episodes of SA, respectively.

\section{Concomitant conditions}

The most frequent concomitant conditions in our study population are listed in Table 4: cardiovascular disease $(n=45,41.3 \%)$, including heart disease $(n=$ $37,33.9 \%)$ and peripheral arterial disease $(n=19$, $17.4 \%)$; pre-existing rheumatic disease $(n=39$, $35.8 \%)$, including osteoarthritis $(n=24,22.0 \%)$, gout/chondrocalcinosis $(n=15,13.8 \%), \quad$ RA and other inflammatory rheumatic diseases $(n=7,6.4 \%)$. Furthermore, 6 of the 7 latter patients were taking immunosuppressants. Diabetes mellitus and cancer were noted in $26(23.9 \%)$ and $22(20.2 \%)$ patients, respectively. Concomitant or pre-existing skin involvement (eschars and/or leg ulcers) was found in 16 (14.7\%) patients. Patients with small joint involvement differed significantly from patients with large joint involvement in terms of cardiovascular disease $(17.6 \%$ vs. $52.0 \%$, respectively; $p<0.01)$ and diabetes $(11.8 \%$ vs. $29.3 \%, p=0.04)$ (Table 1$)$.

Table 1 Characteristics of the study participants

\begin{tabular}{|c|c|c|c|c|c|}
\hline Variables & Number & $\begin{array}{l}\text { All participants } \\
(n=109)\end{array}$ & $\begin{array}{l}\text { Small joint involvement } \\
(n=34)\end{array}$ & $\begin{array}{l}\text { Large joint involvement } \\
(n=75)\end{array}$ & p-value \\
\hline Age, years & 109 & $62[16-96]$ & $52.5[16-89]$ & 65 [17-96] & $<0.01$ \\
\hline Male gender, n (\%) & 109 & $74(67.9)$ & $19(55.9)$ & $55(73.3)$ & 0.07 \\
\hline Body mass index $\left(\mathrm{kg} / \mathrm{m}^{2}\right)$ & 80 & $25[14.5-48]$ & $24.1[17-40.4]$ & $26.05[14.5-48]$ & 0.25 \\
\hline Creatinine clearance (ml/min) & 105 & $80[5-150]$ & 84 [13-150] & $78[5-150]$ & 0.35 \\
\hline C-reactive protein (mg/l) & 102 & $120[3-640]$ & $23[3-230]$ & $166[3-640]$ & $<0.01$ \\
\hline Length of hospital stay (days) & 109 & $16[2-216]$ & $6[2-56]$ & $21[2-216]$ & $<0.01$ \\
\hline Duration of oral therapy (days) & 102 & $52.5[3-112]$ & 42 [3-84] & $84[10-112]$ & $<0.01$ \\
\hline Department, n (\%) & 109 & & & & \\
\hline -Rheumatology & & $51(47.8)$ & $5(14.7)$ & $46(61.4)$ & \\
\hline -Orthopaedics & & $37(33.9)$ & $28(82.3)$ & $9(12.0)$ & \\
\hline -Infectious Dis. & & $20(18.3)$ & $1(3.0)$ & $19(25.3)$ & \\
\hline -Geriatric Med. & & $1(<1)$ & $0(<1)$ & $1(1.3)$ & $<0.01$ \\
\hline Staphylococcus aureus, n (\%) & 109 & $59(59.0)$ & $16(51.6)$ & $43(62.3)$ & 0.31 \\
\hline Diabetes, n (\%) & 109 & $26(23.8)$ & $4(11.8)$ & $22(29.3)$ & 0.04 \\
\hline Cardiovascular disease, n (\%) & 109 & $45(41.3)$ & $6(17.6)$ & $39(52.0)$ & $<0.01$ \\
\hline Cancer, n (\%) & 109 & $22(20.2)$ & $4(11.8)$ & $18(24.0)$ & 0.14 \\
\hline Surgery, n (\%) & 109 & $60(55.0)$ & $26(75.5)$ & $34(45.3)$ & $<0.01$ \\
\hline All-cause death, n (\%) & 107 & $19(17.8)$ & $2(6.2)$ & $17(22.7)$ & 0.04 \\
\hline Death directly attributable to SA, n (\%) & 107 & $6(5.6)$ & $0(<1)$ & $6(8.0)$ & 0.10 \\
\hline Poor functional outcome, n (\%) & 88 & $28(31.8)$ & $7(23.3)$ & $21(36.2)$ & 0.22 \\
\hline
\end{tabular}

Data are reported as the median [range]. Statistically significant results are indicated in bold type 
Table 2 Joint sites involved with SA (109 adult patients with confirmed SA (including 11 with multiple joint involvements with a total of 130 infected joints))

\begin{tabular}{lllll}
\hline Joint involved & $\begin{array}{l}\text { Number } \\
(n=109)\end{array}$ & Percent & $\begin{array}{l}\text { Number } \\
(n=130)\end{array}$ & Percent \\
\hline $\begin{array}{l}\text { Small joint involvement } \\
\text { (fingers and toes) }\end{array}$ & 34 & 31.2 & 36 & 27.7 \\
Knee & 25 & 22.9 & 31 & 23.9 \\
$\begin{array}{l}\text { Shoulder (glenohumeral or } \\
\text { acromioclavicular) }\end{array}$ & 16 & 14.7 & 20 & 15.4 \\
Hip & 12 & 11.0 & 16 & 12.3 \\
Ankle or subtalar & 9 & 8.2 & 14 & 10.8 \\
Sacroiliac & 5 & 4.6 & 5 & 3.8 \\
Symphisis pubis & 3 & 2.7 & 3 & 2.3 \\
Wrist & 2 & 1.9 & 2 & 1.5 \\
Elbow & 2 & 1.9 & 2 & 1.5 \\
Sternoclavicular & 1 & 0.9 & 1 & 0.8 \\
\hline
\end{tabular}

\section{Diagnosis and presentation}

The median [range] time to presentation was 7 [1-120] days. A history of fever was recorded in $44 \%$ of cases, with rigor in $27 \%$ and sweating in only $16 \%$. Fever $\left(>37.5{ }^{\circ} \mathrm{C}\right)$ and confusion on admission were respectively detected in only about $46 \%$ (48 of 104) and $12 \%$ (13 of 109) of cases.

The CRP level was elevated $(>3.2 \mathrm{mg} / \mathrm{l})$ in $96.1 \%$ of the 102 tested patients (median [range]: 120 [3-640] $\mathrm{mg} / \mathrm{l})$. Moreover, CRP levels were lower in patients with small joint involvement than in those with large joint involvement (23 [3-230] $\mathrm{mg} / \mathrm{l}$ vs. 166 [3-640] $\mathrm{mg} / \mathrm{l}$, respectively, $p<0.01)$. Serum procalcitonin levels were rarely determined (in fewer than $30 \%$ of patients). The median creatinine clearance rate was 80 [5-150] $\mathrm{ml} / \mathrm{min}$ in the 105 tested patients, with variously $<15 \mathrm{ml} / \mathrm{min}$ ( $n$

Table 3 Organisms identified as causes of SA

\begin{tabular}{ll}
\hline Organism & Number $(n=109)$ \\
\hline Staphylococcus aureus & 54 \\
Staphylococcus coagulase-negative & 5 \\
Streptococcus & 11 \\
- $\beta$-haemolytic streptococci & 7 \\
- S. pneumoniae & 2 \\
- Other streptococci & 2 \\
Enterococcus & 1 \\
Pasteurella & 7 \\
Coliform bacilli & 6 \\
Neisseria gonorrhoeae & 3 \\
Other & 4 \\
Mixed infections & 9 \\
Unknown & 9 \\
\hline
\end{tabular}

=4), $15-29 \mathrm{ml} / \mathrm{min}(n=7), 30-59 \mathrm{ml} / \mathrm{min}(n=17), 60$ $89 \mathrm{ml} / \mathrm{min}(n=34)$ and $\geq 90 \mathrm{ml} / \mathrm{min}(n=43)$ (Table 1$)$. The total white cell count was elevated $(>10,000)$ in only $50 \%$ of the 105 tested patients. Anaemia (haemoglobin $<12 \mathrm{~g} / \mathrm{dl}$ ) was observed in $50 \%$ of the 105 tested patients.

One hundred and nine patients had at least one sample sent for microbiological testing. One hundred of these $(91.7 \%)$ had a positive culture. Specifically, organisms were identified in the synovial fluid in 86 (84.3\%) of the 102 patients that had synovial fluid analysed. Of the 79 patients who had blood cultures, 31 (39.2\%) were positive. In 11 of these, blood cultures were the only positive result. Forty three patients had synovial fluid sent in blood culture media and 30 (69.8\%) were positive. In just one case, this was the only positive microbiological test. Lastly, 16S rRNA gene sequencing was the only positive microbiological test in 2 patients (revealing Streptococcus agalactiae and Streptobacillus moniliformis, respectively).

Transoesophageal echocardiography and transthoracic echocardiography were performed in 17 and 48 cases, respectively, and enabled the detection of four cases of infectious endocarditis.

\section{Treatment}

All patients were hospitalized. The median length of hospital stay (LOS) was 16 [2-216] days. The duration of treatment was very variable, with median durations of intravenous therapy and oral therapy of 8 [2-31] days and 52.5 [3-112] days, respectively. It is noteworthy that initial intravenous therapy was administered in 95 of the 109 cases $(87.1 \%)$. Interestingly, patients with small joint involvement had a significantly shorter LOS (6 [2-56], vs. 21 [2-216] days for patients with large joint involvement; $p<0.01$ ) and duration of oral therapy (42 [3-84] vs. 84 [10-112], respectively; $p<0.01$ ) (Table 1 ). Various antibiotic combinations were used in initial intravenous treatment, with the most common being aminoglycoside and oxacillin $(n=34)$, aminoglycoside and vancomycin $(n=10)$, aminoglycoside and amoxicillin $(n=9)$ and aminoglycoside and amoxicillin/clavulanic acid $(n=8)$. In terms of oral therapy, the most commonly used combinations were rifampicin and fluoroquinolones $(n=35)$, followed by dalacin and fluoroquinolones $(n$ $=15)$. Sixty of the 109 patients $(55 \%)$ required surgical lavage (arthroscopic washout in 8 cases and arthrotomy/washout in 52 cases).

\section{Disease outcomes}

The disease outcomes data for two of the 109 patients $(<2 \%)$ were incomplete because the patients could not be contacted. Both of these cases (a 17-year-old male 
Table 4 Concomitant conditions

\begin{tabular}{llc}
\hline Concomitant conditions & Number & Percent \\
\hline Heart disease & 37 & 33.9 \\
Current smokers & 36 & 33.0 \\
Diabetes mellitus & 26 & 23.9 \\
Osteoarthritis & 24 & 22.0 \\
Previous cancer & 22 & 20.2 \\
Peripheral arterial disease & 19 & 17.4 \\
Kidney disease & 17 & 13.8 \\
Gout/chondrocalcinosis & 15 & 13.8 \\
Alcohol abuse & 13 & 11.9 \\
Lung disease & 12 & 11.0 \\
Oral corticosteroids & 10 & 9.2 \\
Skin ulceration & 10 & 9.2 \\
Eschars & 9 & 8.2 \\
Liver disease & 7 & 6.4 \\
Rheumatoid arthritis and other & 7 & 6.4 \\
inflammatory rheumatic disease & & 2.8 \\
Intra-articular corticosteroids & 3 & 1.8 \\
Intravenous drug abuse & 2 &
\end{tabular}

and a 60-year-old female) involved finger joint infection with $S$. aureus. The median duration of follow-up (in patients surviving for more than 6 months) was 17 months [6-43].

Nineteen of the patients with SA (17.8\%) died; 6 of these mortalities were considered to be directly attributable to SA (5.6\%) and occurred soon after the onset of the SA (median: 24 days [1-42]). The remaining 13 patients died from causes other than SA: cardiovascular disease $(n=6)$, bed confinement $(n=3)$, kidney failure $(n=1)$, macrophage activation syndrome $(n=1)$, suicide $(n=1)$ and cancer $(n=1)$.

Our univariate analysis suggested that older age (odds ratio (OR) [95 \% confidence interval] per year: 1.09 [1.02-1.19]; $p=0.023$ ), CRP (OR per unit: 1.01 [1.0061.02]; $p=0.002$ ), bacteraemia (OR 15.20 [2.31-298.70]; $p=0.015$ ), skin involvement (OR: 14.83 [2.62-115.71]; $p$ $=0.003)$, RA or other inflammatory rheumatic diseases (OR 9.60 [1.14-64.04]; $p=0.021$ ), diabetes mellitus (OR 7.18 [1.31-54.31]; $p=0.028)$, confusion on admission (OR 9.10 [1.51-55.39]; $p=0.012$ ) and a low creatinine clearance rate (OR per unit: 0.96 [0.92-0.99]; $p=0.009$ ) were predictive of mortality directly attributable to SA (Table 5).

The morbidity was also considerable, since a poor functional outcome was observed in 28 of the 88 eligible patients $(31.8 \%)$ : eleven patients had severe functional deterioration; amputation was necessary in 8 patients, osteosynthesis in 4 patients and joint replacement in 5 patients. In terms of the hip joint, a poor functional outcome was found in 8 of the 10 eligible patients with severe functional deterioration in 5 patients and joint replacement in 3 patients. Data on univariate risk factors for poor functional outcome are summarized in Table 6. The analysis suggested that older age (OR per year: 1.02 [1.001-1.05]; $p=0.049$ ), hip joint involvement (OR: 11.60 [2.65-81.29], $p=0.003)$, skin involvement (OR: $6.33[1.60-31.55] ; p=0.012$ ), time to presentation (OR per day: 1.02 [1.002-1.04], $p=0.034$ ) and a low creatinine clearance rate (OR per unit: 0.98 [0.97-0.99]; $p=$ 0.013 ) were associated with a poor functional outcome.

\section{Discussion}

This study of adult patients with SA specifically included only the 109 cases with native joint infection admitted to our university hospital. The duration of follow-up enabled us to determine the outcomes (including mortality directly attributable to SA). The frequency of death directly attributable to SA (5.6\%) was lower and the poor functional outcome rate $(31.8 \%)$ was higher than expected. Predictive factors of death directly attributable to SA were older age, high serum CRP levels, RA and other inflammatory disease, diabetes mellitus, and confusion on admission, bacteriema, skin involvement (leg ulcers and/or eschars) and a low creatinine clearance rate. Older age, hip joint involvement, skin involvement, a longer time to presentation and a low creatinine clearance rate were predictive of a poor functional outcome.

In terms of identifying individual cases, complete reliance on retrospective HAI data would have been a problem. Fortunately, consecutive patients with SA diagnosed between November 2010 and December 2013 were reported to a prospective diagnosis registry by our clinicians. Accordingly, 22 patients (20\% of the total) were identified solely through the diagnosis registry. Children, adolescents and patients with prosthetic joint SA were excluded from the study because we considered that (in comparison with adult patients with native SA) pathogens, treatments, outcomes, and risk factors for the development of SA might differ [14, 19-23].

Our results confirmed literature data on the demographics (age and gender) of patients with SA [12, 24], the affected joints, the pathogens and the risk factors. Surprisingly, the most common sites involved were small joints $(31.2 \%$, which is much higher than the literature values of below $10 \%[5,6])$. This disparity might be related to our inclusion criteria, since SA as a result of a skin wound is sometimes excluded from studies in this field; in the present study, this condition was frequently observed in patients with small joint involvement. Our results again emphasize that multiple joint involvement is not rare [1]. Indeed, 11 of our 109 patients had several affected joints. The spectrum of causative organisms was similar to that reported in previous studies, with the 
Table 5 Univariate analysis of factors possibly associated with mortality attributable directly to septic arthritis

\begin{tabular}{|c|c|c|c|c|c|}
\hline & Yes $(N=6)$ & No $(N=101)$ & p-value & Odds ratio $[95 \% \mathrm{Cl}]$ & $\begin{array}{l}\text { Univariate analysis } \\
p \text {-value }\end{array}$ \\
\hline Age (years) & $82.5[59-96]$ & $62.0[16-95]$ & 0.017 & $1.09[1.02-1.19]$ & 0.023 \\
\hline Gender (Female) & $3(50 \%)$ & $31(31 \%)$ & 0.380 & $2.26[0.40-12.80]$ & 0.335 \\
\hline Knee involvement & $3(50 \%)$ & $22(22 \%)$ & 0.138 & $3.59[0.63-20.61]$ & 0.133 \\
\hline Hip involvement & $0(<1 \%)$ & $12(12 \%)$ & 1 & not defined & 0.993 \\
\hline Multiple joint involvement & $2(33 \%)$ & $8(8 \%)$ & 0.097 & $5.81[0.73-35.11]$ & 0.062 \\
\hline Cardiovascular disease & $3(50 \%)$ & $42(42 \%)$ & 0.694 & $1.40[0.25-7.91]$ & 0.686 \\
\hline Skin involvement & $4(67 \%)$ & $12(12 \%)$ & 0.004 & $14.83[2.62-115.71]$ & 0.003 \\
\hline Rheumatoid arthritis and related conditions & $2(33 \%)$ & $5(5 \%)$ & 0.049 & $9.60[1.14-64.04]$ & 0.021 \\
\hline Previous cancer & $3(50 \%)$ & $19(19 \%)$ & 0.100 & $4.32[0.75-24.95]$ & 0.087 \\
\hline Diabetes mellitus & $4(67 \%)$ & $22(22 \%)$ & 0.030 & $7.18[1.31-54.31]$ & 0.028 \\
\hline Time to presentation (days) & $11[4-24]$ & $7[0-120]$ & 0.695 & $0.98[0.92-1.02]$ & 0.507 \\
\hline Confusion on admission & $3(50 \%)$ & $10(10 \%)$ & 0.023 & $9.10[1.51-55.39]$ & 0.012 \\
\hline Creatinine clearance (MDRD, $\mathrm{ml} / \mathrm{min}$ ) & $32[23-66]$ & $81[5-150]$ & 0.003 & $0.96[0.92-0.99]$ & 0.009 \\
\hline C-reactive protein (mg/l) & $375[88-640]$ & $120[3-465]$ & 0.003 & $1.01[1.006-1.02]$ & 0.002 \\
\hline Staphylococcus aureus & $4(67 \%)$ & $53(58 \%)$ & 1 & $1.47[0.27-11]$ & 0.665 \\
\hline Joint surgery & $1(17 \%)$ & $57(56 \%)$ & 0.091 & $0.15[0.01-1.002]$ & 0.093 \\
\hline Bacteraemia & $5(83 \%)$ & $25(25 \%)$ & 0.006 & $15.20[2.31-298.70]$ & 0.015 \\
\hline Small joint involvement & $0(<1 \%)$ & $32(32 \%)$ & 0.175 & not defined & 0.993 \\
\hline
\end{tabular}

MDRD Modification of Diet in Renal Disease

Statistically significant results are indicated in bold type

Table 6 Univariate analysis of factors possibly associated with a poor functional outcome in septic arthritis

\begin{tabular}{|c|c|c|c|c|c|}
\hline & Yes $(N=28)$ & No $(N=60)$ & $p$-value & Odds ratio $[95 \% \mathrm{Cl}]$ & $\begin{array}{l}\text { Univariate analysis } \\
p \text {-value }\end{array}$ \\
\hline Age (years) & 64.0 [36-90] & $54.5[16-95]$ & 0.076 & $1.02[1.001-1.05]$ & 0.049 \\
\hline Gender (Female) & $10(36 \%)$ & $19(32 \%)$ & 0.707 & $1.20[0.46-3.07]$ & 0.707 \\
\hline Knee involvement & $3(11 \%)$ & $13(22 \%)$ & 0.252 & $0.43[0.09-1.50]$ & 0.224 \\
\hline Hip involvement & $8(29 \%)$ & $2(3 \%)$ & 0.001 & $11.60[2.65-81.29]$ & 0.003 \\
\hline Multiple joint involvement & $3(11 \%)$ & $4(7 \%)$ & 0.675 & $1.68[0.31-8.17]$ & 0.517 \\
\hline Small joint involvement & $7(25 \%)$ & $23(38 \%)$ & 0.219 & $0.54[0.19-1.41]$ & 0.223 \\
\hline Cardiovascular disease & $12(43 \%)$ & $19(32 \%)$ & 0.306 & $1.62[0.64-4.10]$ & 0.308 \\
\hline Skin involvement & 7 (25\%) & $3(5 \%)$ & 0.010 & $6.33[1.60-31.55]$ & 0.012 \\
\hline Rheumatoid arthritis and related conditions & $1(4 \%)$ & $3(5 \%)$ & 1 & $0.70[0.03-5.79]$ & 0.765 \\
\hline Previous cancer & $8(29 \%)$ & $7(12 \%)$ & 0.049 & $3.03[0.97-9.73]$ & 0.056 \\
\hline Diabetes mellitus & $7(25 \%)$ & $13(22 \%)$ & 0.728 & $1.21[0.40-3.40]$ & 0.728 \\
\hline Time to presentation (days) & 15 [0-105] & $5[0-91]$ & 0.016 & $1.02[1.002-1.04]$ & 0.034 \\
\hline Creatinine clearance (MDRD, $\mathrm{ml} / \mathrm{min}$ ) & $71[5-130]$ & $94[29-150]$ & 0.019 & $0.98[0.97-0.99]$ & 0.013 \\
\hline C-reactive protein (mg/l) & 120 [3-342] & $105.5[3-465]$ & 0.862 & $0.999[0.995-1.004]$ & 0.839 \\
\hline Staphylococcus aureus & $15(58 \%)$ & $29(55 \%)$ & 0.802 & $1.13[0.44-2.96]$ & 0.803 \\
\hline Joint surgery & $17(61 \%)$ & $33(55 \%)$ & 0.614 & $1.26[0.51-3.21]$ & 0.615 \\
\hline
\end{tabular}

MDRD Modification of Diet in Renal Disease

Statistically significant results are indicated in bold type 
Gram-positive organisms S. aureus and Streptococci being responsible for $60 \%$ of cases [6]. Septic arthritis due to MRSA was rare during the present study period (9 cases, accounting for $8.3 \%$ of all episodes) [25]. We found that a high proportion (35.8 \%) of patients with SA had underlying rheumatic disease, as reported previously $[10,12]$. However, few patients (relative to the literature data) were affected by RA $(n=4)$ or other inflammatory rheumatic diseases $(n=3)[5,12]$. Surprisingly, pre-existing or concomitant cancer was reported in 22 patients. These conditions are rarely reported on in this kind of study. Intra-articular corticosteroid injection and human immunodeficiency virus infection were also quite rare $[7,10,11]$.

Our data strongly suggested that a sample of synovial fluid should be obtained before antibiotic treatment is initiated. However, it is also clear that blood cultures contribute to the diagnosis and should not be omitted. Cultures of joint aspirate and/or blood were positive in $89 \%$ of cases; this proportion is similar to that observed in previous studies $[6,26]$. The aetiology of SA could not be determined in only 9 cases $(8.2 \%)$. Moreover, the use of blood culture methods for synovial fluids might not be of value; further studies are needed to unambiguously resolve this issue.

In the literature, mortality rates range from 4 to $42 \%$ [15]. This broad range may be due to study-to-study difference in patient comorbidities, inclusion criteria (children, prosthetic joint infections, etc.) and clinical presentations (since SA can present as an isolated disease or as part of a sepsis syndrome. Two series published between 1997 and 1999 reported mortality rates of 11.5 and $10 \%$, respectively [5, 6], and Gupta et al. reported a value of $11 \%$ in 2001 [12]. One series found a rate of $4 \%$ [24] which is quite similar to our value of $5.6 \%$. More recently, Munoz-Egea et al. [27] and Lim et al. [28] reported rates of $7.7 \%$ and $5.5 \%$, respectively. Surprisingly, Geirsson et al. found a mortality rate of $1.8 \%$ in a study of 253 cases (69 children and 184 adults) diagnosed in Iceland between 1990 and 2002; an iatrogenic aetiology was noted in $41.8 \%$ of the adults [7]. One possible explanation for the low mortality rate encountered in the present study is our decision to exclude prosthesis infections, since mortality rates for these patients are usually closer to $20 \%$ [5]. Another possible explanation relates to the large number of cases of small-joint infections (fingers and toes), which generally correspond to limited-scale disease not accompanied by sepsis syndrome. Indeed, CRP levels were higher in patients with large joint involvement than in those with small joint involvement, and an elevated CRP level was a strong risk factor for deaths directly attributable to SA. To the best of our knowledge, our results are the first to highlight CRP in this respect. Although CRP per se was not tested as a predictive factor in previous studies $[5,6]$ an elevated erythrocyte sedimentation rate was predictive of death [12]. We do not have an obvious explanation for the predictive value of skin involvement (leg ulcers and/or eschars), although Gupta et al. [12] and Ravindran et al. [24] also found a higher rate of mortality in patients with leg ulcers. Again, the presence of eschars (whether previous or concomitant) had never previously been tested as predictive factor for death in SA. However, leg ulcers and above all eschars are found in the frailest patients; this perhaps explains why these features are associated with a high mortality rate. We also confirmed that older age, diabetes mellitus, bacteraemia, chronic renal failure, inflammation [29] and confusion [6] on admission are risk factors associated with death directly attributable to AS.

Furthermore, we observed substantial morbidity; a poor functional outcome occurred in $32 \%$ of the patients (in line with the literature data) $[5,6,24]$. In the present study, older age, hip joint involvement, longer time to presentation, previous or concomitant skin involvement and a low creatinine clearance rate were associated with functional impairment. High morbidity in patients with SA at the hip joint can be explained by the frequent need for resection arthroplasty. We do not have obvious explanations for the correlation with skin involvement and a low creatinine clearance rate, although both conditions are associated with frailty (which probably prevented adequate recovery and rehabilitation). Longer time to presentation was also highlighted as a risk factor in the present study. This is particularly relevant, and physicians should be aware of this aspect. Moreover, the suspicion that surgical lavage may be associated with a poor outcome was not confirmed by our present results $[6,19]$.

Our study had several limitations. Firstly, the study was hospital-based (rather than population-based) and so its findings cannot be extrapolated to other populations. Secondly, our study had a relatively small number of patients. However, SA is a rare condition, and the implementation of multicentre, prospective, randomized controlled trials (to ensure large number of patients) is logistically difficult (albeit highly desirable). Thirdly, our study involved an unusually high proportion of adults with small joint involvement. However, small joint involvement emphasizes the broad spectrum of conditions in SA, since it can present as an isolated disease or as part of a sepsis syndrome. Lastly, the study was ambispective (rather than prospective), which prevented us from obtaining additional data (such as the patients' functional status on admission, social status and education level). 


\section{Conclusions}

The present study emphasises the continuing poor outcomes following native SA in adults. Better patient outcomes will require additional research into the optimal management of SA (improved diagnosis, joint drainage methods, antibiotic regimens, treatment duration, etc.).

\section{Key messages}

Septic arthritis continues to be associated with a considerable degree of morbidity and mortality.

C-reactive protein might a valuable predictive factor for death directly attributable to SA.

Hip joint involvement is associated with a poor functional outcome.

\section{Ethics approval and consent to participate}

The study was designed in accordance with the ethical standards of our hospital Ethics Committee (Amiens University Hospital). In view of the study's design, no written informed consent to participation was necessary in accordance with our ethical committee.

\section{Availability of data and materials}

Data supporting our findings can be asked to Paccou Julien (julienpaccou@yahoo.fr)

\section{Abbreviations \\ BMI: body mass index; CRP: C-reactive protein; HAl: hospital activity index LOS: length of hospital stay; MRSA: methicillin-resistant staphylococcus aureus; OR: odds ratio; RA: rheumatoid arthritis; SA: septic arthritis.}

\section{Competing interests}

Ferrand Julien, El Samad Youssef, Brunschweiler Benoit, Grados Franck, Dehamchia-Rehailia Nassima, Séjourné Alice, Schmit Jean-Luc, Gabrion Antoine, Fardellone Patrice and Paccou Julien declare that they have no conflict of interest.

\section{Authors' contributions}

$J F, Y E S, B B, F G, N D R, A S, J L S, A G, P F$ and JP designed and initiated the study. JF, NDR, AS and JP collected the data. JF and JP analysed and interpreted all the data, and wrote a first draft of the paper. All authors read, commented on and approved the final manuscript.

\section{Acknowledgements}

We thank Jonathan Meynier for performing the statistical analysis We thank David Fraser (Biotech Communication SARL, Damery, France) for copy-editing assistance.

\section{Funding}

No funding sources were necessary for this study.

\section{Author details}

'Department of Rheumatology, Amiens University Hospital, F-80054 Amiens, France. ${ }^{2}$ Department of Infectious Diseases, Amiens University Hospital, F-80054 Amiens, France. ${ }^{3}$ Department of Orthopaedics, Amiens University Hospital, F-80054 Amiens, France.

Received: 1 September 2015 Accepted: 5 May 2016 Published online: 01 June 2016

\section{References}

1. Mathews CJ, Weston VC, Jones A, Field M, Coakley G. Bacterial septic arthritis in adults. Lancet. 2010;375:846-55.

2. Mathews CJ, Coakley G. Septic arthritis: current diagnostic and therapeutic algorithm. Curr Opin Rheumatol. 2008;20:457-62.

3. Mathews CJ, Kingsley G, Field M, et al. Management of septic arthritis: a systematic review. Ann Rheum Dis. 2007;66:440-5.

4. Morgan DS, Fisher D, Merianos A, Currie BJ. An 18 year clinical review of septic arthritis from tropical Australia. Epidemiol Infect. 1996;117: 423-28.

5. Kaandorp CJ, Dinant HJ, van de Laar MA, Moens HJ, Prins AP Dijkmans BA. Incidence and sources of native and prosthetic joint infection: a community based prospective survey. Ann Rheum Dis. 1997:56:470-75

6. Weston VC, Jones AC, Bradbury N, Fawthrop F, Doherty M. Clinical features and outcome of septic arthritis in a single UK health district 1982-1991. Ann Rheum Dis. 1999:58:214-19.

7. Geirsson AJ, Statkevicius S, Vikingsson A. Septic arthritis in Iceland 19902002: increasing incidence due to iatrogenic infections. Ann Rheum Dis. 2008;67:638-43.

8. Favero M, Schiavon F, Riato L, Carraro V, Punzi L. Rheumatoid arthritis is the major risk factor for septic arthritis in rheumatological settings. Autoimmun Rev. 2008;8:59-61.

9. Edwards CJ, Cooper C, Fisher D, Field M, van Staa TP, Arden NK. The importance of the disease process and disease-modifying antirheumatic drug treatment in the development of septic arthritis in patients with rheumatoid arthritis. Arthritis Rheum. 2007;57:1151-7.

10. Kaandorp CJ, Van Schaardenburg D, Krijnen P, Habbema JD, van de Laar MA. Risk factors for septic arthritis in patients with joint disease. Arthritis Rheum. 1995:38:1819-25.

11. Vassilopolous D, Chalasani P, Jurado RL, Workowski K, Agudelo CA. Musculoskeletal infections in patients with human immunodeficiency virus infection. Med (Baltimore). 1997;76:284-94.

12. Gupta MN, Sturrock RD, Field M. A prospective 2-year study of 75 patients with adult-onset septic arthritis. Rheumatology. 2001;40:24-30.

13. Coakley G, Mathews C, Field M, on behalf of the British Society for Rheumatology Standards, Guidelines and Audit Working Group, et al. BSR \& $\mathrm{BHPR}, \mathrm{BOA}, \mathrm{RCGP}$ and BSAC guidelines for management of the hot swollen joint in adults. Rheumatology (Oxford). 2006;45:1039-41.

14. Kaandorp CJ, Krijnen P, Moens HJ, Habbema JD, van Schaardenburg D. The outcome of bacterial arthritis: a prospective community based study. Arthritis Rheum. 1997;40:884-92.

15. Fangtham M, Baer AN. Methicillin-resistant Staphylococcus aureus septic arthritis in adults: case report and review of the literature. Semin Arthritis Rheum. 2012:41:604-10.

16. Clerc O, Prod'hom G, Greub G, Zanetti G, Senn L. Native septic arthritis: a review of 10 years of experience and lessons from empirical antibiotic therapy. J Antimicrob Chemother. 2011;66:1168-73.

17. Shirtliff ME, Mader JT. Acute septic arthritis. Clin Microbiol Rev. 2002;15:527-44.

18. Newman JH. Review of septic arthritis throughout the antibiotic era. Ann Rheum Dis. 1976:35:198-205.

19. Goldenberg DL, Brandt KD, Cohen AS, Cathcart ES. Treatment of septic arthritis. Comparison of needle aspiration and surgery as initial modes of joint drainage. Arthritis Rheum. 1975;18:83-90.

20. Cooper C, Cawley MI. Bacterial arthritis in an English health district: a 10 year review. Ann Rheum Dis. 1986;45:458-63.

21. Rosenthal J, Bole GG, Robinson WD. Acute non gonococcal infectious arthritis. Evaluation of risk factors, therapy, and outcome. Arthritis Rheum. 1980;23:889-97.

22. Cohen R, Grimprel E. Child osteoarticular infections: statements and perspectives. Arch Pediatr. 2007;14 Suppl 2:S79-80.

23. Garcia-Arias M, Balsa A, Mola EM. Septic arthritis. Best Pract Res Clin Rheumatol. 2011;25:407-21.

24. Ravindran V, Logan IE, Bourke B. Medical vs surgical treatment for the native joint in septic arthritis: a 6-year, single UK academic centre experience. Rheumatology. 2009;48:1320-2.

25. Dubost JJ, Couderc M, Tatar Z, et al. Three-decade trends in the distribution of organisms causing septic arthritis in native joints: Single-centre study of 374 cases. Joint Bone Spine. 2014;81:438-40.

26. Shmerling RH. Synovial fluid analysis: a critical reappraisal. Rheum Dis Clin North Am. 1994;20:503-12. 
27. Muñoz-Egea MC, Blanco A, Fernández-Roblas R, Gadea I, García-Cañete J, Sandoval E, Valdazo M, Esteban J. Clinical and microbiological characteristics of patients with septic arthritis: A hospital-based study. J Orthop. 2014;11: 87-90.

28. Lim SY, Pannikath D, Nugent K. A retrospective study of septic arthritis in a tertiary hospital in West Texas with high rates of methicillin-resistant Staphylococcus aureus infection. Rheumatol Int. 2015;35:1251-6.

29. Maneiro JR, Souto A, Cervantes EC, Mera A, Carmona L, Gomez-Reino $\mathrm{JJ}$. Predictors of treatment failure and mortality in native septic arthritis. Clin Rheumatol. 2014; [Epub ahead of print].

Submit your next manuscript to BioMed Central and we will help you at every step:

- We accept pre-submission inquiries

- Our selector tool helps you to find the most relevant journal

- We provide round the clock customer support

- Convenient online submission

- Thorough peer review

- Inclusion in PubMed and all major indexing services

- Maximum visibility for your research

Submit your manuscript at www.biomedcentral.com/submit
Biomed Central 